Maija Hirvonen

FT, tutkijatohtori, Helsingin yliopisto

Mikko Ojanen

TM, Lappeenrannan seurakunnan kappalainen

\title{
Kun ei näe \\ - audiovisuaalisen kulttuurin saavuttamattomuus sokean kuulokulmasta
}

Näkeminen ja katsominen ovat suurimmalle osalle meistä luonnollista toimintaa, jopa niin olennainen osa meitä, ettemme kiinnitä niihin edes huomiota. Kuitenkin maailmanlaajuisesti elää ainakin 300 miljoonaa ihmistä, joille näkeminen ei ole itsestään selvää. Sokeita arvioidaan olevan 39 miljoonaa ja ihmisiä, joilla on näönalenema, 246 miljoonaa (WHO 2014). Suurin osa maailman näkövammaisista elää kehittyvissä maissa ja suurin osa vammoista ( $80 \%$ ) voitaisiin estää tai parantaa (emt.). Suomessakin, joka luetaan kehittyneeksi ja korkeatasoisen lääketieteellisen hoidon maaksi, näkövammaisia elää arviolta noin 70 000. Näkövammaisten määrä on nousussa korkean elintason maissa väestön ikääntymisestä johtuen. (Ojamo 2015, 17-18.) Suomessa ja muualla elää siis kymmeniä tuhansia, jopa miljoonia ihmisiä, jotka jäävät osittain visuaalisen ja audiovisuaalisen kulttuurin ulkopuolelle.

$\mathrm{Me}$, näkevä tutkija sekä sokea pappi, tarkastelemme tässä kirjoituksessa suomalaista audiovisuaalista kulttuuria syntymäsokean henkilön kuulokulmasta sekä arvioimme haasteita, joita syrjäytyminen siitä asettaa. Esittelemme myös keinoja, joilla kulttuuriin osallistumista ja audiovisuaalisen sisällön saavutettavuutta voisi parantaa.

Millaisena televisiotarjonta näyttäytyy tai miltä se kuulostaa, kun ei näe? Miksi sokeat ylipäätään katsovat televisiota (kyllä, fraasi "katsoa televisiota" on vakiintunut eikä sitä ole syytä muuttaa esimerkiksi muotoon "kuunnella televisiota") tai miksi he käyvät elokuvissa - eikö radio olisi sopivampi tapa osallistua kulttuuriin? Keskitymme tekstissämme audiovisuaaliseen mediakulttuuriin ja erityisesti televisioon, sillä se on ikääntyneen väestön ensisijainen media ja siten tärkeä myös näkövammaisille, joista suurin osa on ikääntyneitä. Lisäksi televisio tavoittaa laajoja kansanosia: katsovathan suomalaiset televisiota keskimäärin reilu kolme tuntia päivässä (Finnpanel 2015), ja suosikkiohjelmien kuten Putouksen ja Linnan juhlien katselu kerää kansalaiset yhteen "kansakunnan olohuoneeseen".

\section{Kun ei näe eikä ole nähnyt: sokean elämää marginaalissa jo 60 vuotta}

Mikko Ojanen on 63-vuotias syntymäsokea pappi Lappeenrannasta. Visuaalisesti havaittavaa maailmaa, siis sellaista, mitä ei voi kosketuksen, liikkeen tai muutoin oman kehon kautta hahmottaa, ei ole koskaan ollut hänelle olemassa ilman näkevän henkilön verbaalista kuvailua. "Kerro mitä näet", sokea pyytää näkevältä! 
Visuaalisen kulttuurin hahmottamista silloin, kun ei ole koskaan nähnyt, voisi verrata kielen opiskeluun. Kommunikointi mahdollisimman monen näkevän kanssa vaihtelevissa tilanteissa ja erilaisissa ympäristöissä opettaa ymmärtämään näkeville tärkeitä symboleja ja toimintatapoja. Siinä missä ympäröivää tilaa voi sokeakin - silloin kun se on sopivaa - havainnoida omakätisesti eli tunnustelemalla ja koskemalla, audiovisuaalisen kulttuurin tuotteet ovat välitettyjä: televisio ja elokuva näyttävät asioita, joita ei pääse koskettamaan, jolloin sokealle jää vaihtoehdoksi tulkita niitä äänimaailman ja joissakin tapauksissa myös kielellisen kuvailun välityksellä. Thmisten kohdatessa kiinnitetään usein luontaisesti huomiota toisten - ja itsemme - ulkomuotoon: kasvoihin, ihmisen kokoon, vaatetukseen, käyttäytymiseen ja toimintaan. Näköaistin puuttuessa voi muista ihmisistä saada suoraa tietoa puheen sekä kehosta ja toiminnasta lähtevien äänten kautta, mutta tuntoaistilla, esimerkiksi koskettamalla, on liian harvoin mahdollista saada käsitys toisesta ihmisestä - ellei satuta olemaan hyviä tuttuja! Vieraan ihmisen reviirille meneminen, esimerkiksi koskettamalla hänen kasvojaan, muuta kehoaan tai asuaan, tuntuu kummastakin osapuolesta vaivaannuttavalta, ellei siitä ole aivan erityisesti sovittu.

Näkevien ja sokeiden maailmojen kohdatessa sokeudesta tai näkövammasta kyseleminen saattaa ujostuttaa. Toimittaja Anu Silfverberg kuvaa yhteydenottoaan sokeaan henkilöön: "Soitan sokealle naiselle. Kirjailija Jonna Mononen asuu Australiassa. Meillä on yhteinen kaveri, joten kehtaan pyytää häntä "puhumaan sokeana", vaikka se tuntuu melko typerältä." (Silfverberg 2017.) Tänä kuvien ja videoiden aikakaudella on kuitenkin ymmärrettävää, että ihmiset ovat kiinnostuneita maailmasta, joka on näkemiseltä suljettu. Kysymällä sokeiden kokemuksista voidaan oppia jotakin uutta, kuten sen, että "Mononen on nähnyt ne kuvat, vaikka on syntymäsokea" (emt.). Kuvat syntyvät paitsi näkemällä myös mielikuvina, moniaistisiin kokemuksiin perustuen niin, että yhdellä aistilla saatu tieto synnyttää toisella aistilla koetun mielikuvan (Spence \& Deroy 2013). Esseen Mononen haistaa naistenvaateliikkeen ja tiedostaa siellä olevan naisten kuvia. Hän on myös tunnustellut hajuvesipullon naisfiguuria ja lukenut kirjoista kuvauksia naisista. Toisaalta sokeutta mystifioidaan ja ajatellaan, että sokealle kehittyy ylivertainen kuulo ja suunnattoman hyvä muisti. "Haluan tietää, millaista on, jos näitä kuvia ei ole koskaan elämässään nähnyt. Sen täytyy olla ihmeellistä!" (Silfverberg (2017).

Katsominen ja näkeminen sekä katseen kohteena oleminen ja nähdyksi tuleminen ovat keskeisiä inhimillisiä toimintoja, mutta tarkoittavat hieman eri asioita. Katsominen on aktiivista havainnointia (subjekti eli tekijä on agentiivinen eli tietoisesti toimiva), kun taas näkeminen on siinä mielessä passiivista, että subjekti ei tällöin ole aktiivinen toimija vaan havainto tapahtuu ilman että omaehtoisesti katsoo (vrt. Hirvonen 2013). Ainoastaan näkevät voivat nähdä eli vastaanottaa visuaalisia havaintoja, mutta näkörajoitteisetkin voivat katsoa eli olla visuaalisia toimijoita. Lisäksi myöhemmällä iällä sokeutuneet voivat palauttaa mieliinsä visuaalisia muistikuvia. Analysoimalla sokeiden ja näkevien välistä vuorovaikutusta Hirvonen ja Schmitt (valmisteilla) ovat havainneet, että sokea osallistuja voi ohjata omaa katsomiskäyttäytymistään vuorovaikutukselle relevantilla tavalla ja esimerkiksi nostaa katseensa puhujan suuntaan halutessaan puheenvuoron. Katse on tärkeä viestintäkeino ihmisten kesken: katsomalla jaetaan ja pyydetään puheenvuoroja ja osoitetaan kiinnostusta puheenaiheeseen (Tiittula 2007). ${ }^{1}$ Myös sokeat tietävät olevansa katseiden kohteita

1 Näkemisen akti eli katsominen sosiaalisena toimintana ja vuorovaikutuskeinona voi olla erilainen syntymäsokeilla kuin myöhemmin sokeutuneilla. Katsetta ja muuta multimodaalista vuorovaikutusta tutkitaan Maija Hirvosen tutkimusprojektissa MUTABLE: Multimodal Translation with the Blind (ks. blogs.helsinki.fi/audiodescription). 
ja ymmärtävät sen kulttuuriset ja sosiaaliset implikaatiot, kuten katseen voiman ihmisten välisessä vuorovaikutuksessa.

\section{Televisionkatselua sokein silmin}

Audiovisuaalinen media rakentaa suomalaista kulttuuria luoden yhteisiä kokemuksia. Kun ei näe, voi tuntea jäävänsä syrjään siitä, miten suurista elokuvista tai televisioilmiöistä puhutaan julkisuudessa, työpaikoilla ja kouluissa. Joku voisi kysyä, miksi sokeat ylipäätään katsovat televisiota ja eikö radio riittäisi. Televisio on massamedia, ja vaikka radiokin saavuttaa kansalaiset sankoin joukoin, sen ohjelmat eivät nouse puheenaiheiksi siinä määrin kuin television (ks. Kortti 2016). Ojanen, toinen kirjoittajista, on aktiivinen televisionkatsoja, kuten seuraavasta televisio-ohjelmien katselupäiväkirjasta käy ilmi.

Maanantai: Yle Teemalta tuleva historiallinen draamasarja Rooseveltien suku on helppoa seurattavaa: se on eloisaa kerrontaa selkeällä äänitekstitetyllä äänellä, jonka taustalla kuuluu kauttaaltaan selkeää amerikanenglantia. MTV:n puolella taas rikosdraamasarja Rizzoli \& Isles on suosikki, jonka melkein kaikki jaksot ovat tulleet katsotuiksi. Sen äänet ovat tulleet tutuiksi, ja useimmiten puhujan pystyy tunnistamaan äänitekstin taustalta.

Tiistai: Vuorossa on Yle 1:n Presidentin uusinta tai jokin kotimainen elokuva. Teatraalinen replikointi ja runsas puhe auttavat pysymään mukana, mutta toisaalta juuri puheäänten kautta seurattuina näytteleminen vaikuttaa vanhanaikaiselta ja replikointi pateettiselta tai teennäiseltä. Tämä saa draaman seuraamisen tuntumaan raskaalta, ellei juoni satu olemaan todella mielenkiintoinen. Presidentissä on paljon henkilöitä, joita esittävät tutut näyttelijät. Vaikka puhe kuljettaa juonta, nopeat leikkaukset kohtausten välillä, jotka on helppo havaita katseella, ovat sokealle haasteellisia, koska muutos äänimaailmassa ei välttämättä ole selkeä. Lisäksi mahdollinen ristiriita hahmon ulkoasun tai käytöksen ja ääni-ilmaisun välillä aiheuttaa päänvaivaa, samoin kuin nonverbaalit "pelit" hahmojen välillä. Usein uusintakatselu auttaa muodostamaan ehyen mielikuvan tapahtuneesta. Jos perheen jäsenet katsovat samaa ohjelmaa, ohjelmaa puidaan jälkeenpäin yhdessä.

Keskiviikko: Yle 2:n Syke, sairaaladraama, sisältää yllättävän paljon puhetta ja siksi juonessa pysyy hyvin mukana. Ratkaisevat dramaattiset käänteet näytetään kuitenkin usein kuvakerrontana, jolloin juonen palapeliä on vaikeaa tai jopa mahdotonta koota. Toisaalta näyttelijöiden äänet ovat helposti tunnistettavissa ja ne sisältävät paljon tunteikasta puhetta, joka tuo esiin äänten ja hahmon karaktäärin.

Musiikki heijastaa useimmiten miljöön ja ilmapiirin muutoksia, mutta se voi toisinaan toimia myös vastakohtana kohtauksen kauneudelle tai kauheudelle. Esimerkiksi elokuvassa Kellopeliappelsiini (1971) taustalla soi tuttu ikivihreä Singing in the rain samalla kun näytetään, kuinka jengi pahoinpitelee vanhusta. Jos taas musiikki kilpailee äänenvoimakkuudeltaan lausuttujen repliikkien kanssa, kuulostaa se lähes aina häiritsevältä! Toisaalta musiikin ja muun äänimaailman yhteisvaikutus voi olla suorastaan vangitseva pelkästään kuultunakin, kuten Steven Spielbergin tv-sarjoissa Taistelutoverit ja Tyynenmeren taistelutoverit samoin kuin - trailerista päätellen - syksyllä 2017 ensi-iltansa saavassa Aku Louhimiehen Tuntemattomassa sotilaassa.

2 Äänitekstitys on synteettistä puhetta, joka toistaa ruudulla näkyvän tekstin. Sen saa kuuluville Ylen, MTV:n ja Nelosen kanavilla, kun valitsee äänikieleksi hollannin. Urheilu- ja lastenohjelmien sekä uutislähetysten vieraskielisiä osuuksia ei toistaiseksi äänitekstitetä. Äänitekstitys(ääni) on aina samanlainen, alkuperäisestä kielestä, puhujasta tai ohjelmatyypistä riippumatta. 
Torstai: Yle 2:n Noin viikon uutiset on helppoa kuultavaa, vaikka monet vitseistä perustuvatkin kuviin, tai kuvan ja sanan yhteisvaikutukseen, ja juontajan parodioimien tilanteiden nonverbaaliseen hauskuuteen. Joskus ohjelman seuraaminen ilman käsitystä kuvakerronnasta turhauttaa.

Perjantai: Kerrankin ongelmaton ohjelma: Pressiklubi! Pääpaino on keskustelulla.

Lauantai: MTV:n Putous: muukin perhe katsoo sitä. Spektaakkelissa on paljon korville avautuvaa huumoria, ja sketsihahmot ovat helposti tunnistettavia hokemiensa ja muiden parodioitujen maneeriensa kautta. Kehonkielen havaintojen puuttuminen saa kuitenkin kyllästymään niihin helposti.

Sunnuntai: Yle 1:n Poirot, kirjallisuusfilmatisointi, on helppoa seurattavaa, jos on lukenut Christien kirjat. Näyttelijöiden yläluokkainen puhetapa auttaa tunnistamaan puhujat äänitekstityksen taustalta. Yksittäinen jakso on tarpeeksi pitkä niin, että siihen pääsee ajan mittaan sisälle.

Sokean televisionkatselu nojaa siis kuuloon ja auditiviiseen informaatioon. Elokuvakerronnan musiikki ja ääniefektit sekä näyttelijän esittämän henkilön puhetyyli ohjaavat tulkintaa. Puheäänen ominaisuuksien perusteella voi päätellä henkilön ulkonäköä, käyttäytymistä ja nonverbaalia viestintää. Äänitehosteiden ja niiden ominaisuuksien perusteella voi tehdä päätelmiä tilasta ja paikasta, esimerkiksi etäisyyssuhteista (ks. Hirvonen \& Tiittula 2012). Sieltä täältä eri voimakkuuksilla ja rytmissä kuuluvat äänet luovat käytännöllisesti katsoen maailman sokean katsojan ympärille. ${ }^{3}$ Tähän sisältyy kuitenkin "väärinymmärryksen" tai harhaanjohtamisen vaara, sillä äänet ovat usein monitulkintaisia, jos ne koetaan ilman visuaalista kuvaa tai verbaalista kuvailua. Ojasen kokemuksissa äänimaailma voi myös selventää kerronnan rakennetta: esimerkiksi musiikin jumputtava rytmi ennakoi jotakin pian tapahtuvan, ja äänimaiseman muutos toimii vihjeenä leikkauksesta.

Ehkä onkin vanhanaikaista käsitellä audiovisuaaliseen kulttuuriin osallistumista näköaistin ja visuaalisen havainnoinnin merkityksiä painottaen. Niin kulttuurin kuin käyttäytymisenkin tutkimuksessa ollaan entistä enemmän kiinnostuneita siitä, miten kulttuuriin otetaan osaa koko keholla (esim. Sobchack 2004) ja miten mielikuvat syntyvät muidenkin kuin näköaistin kautta (esim. Lacey \& Lawson 2013). Yllä kuvaamamme esimerkit auditiivisen havainnoinnin monipuolisuudesta osoittavat, että elokuva ja televisio todellakin ovat audiovisuaalista kulttuuria, jossa korvilla ja silmillä molemmilla on merkitystä.

\section{Saavuttamaton saavutettavaksi eli kuvailun kautta kuvakerrontaan}

Kielellinen kuvailu on keino tehdä visuaalinen informaatio saavutettavaksi näkörajoitteisille. Kuvailutulkkaus kielentämisen menetelmänä on käytössä ympäri maailman laissa säädettynä tai vapaaehtoisesti tuotettuna saavutettavuuspalveluna, mutta kuvailutulkatun ohjelmiston määrä vaihtelee. Suomessa on jo kokeiltu kuvailutulkattua elokuvaa elokuvateatterissa, jolloin kävijä lataa etukäteen älylaitteeseen äänitallenteen, joka elokuvan alkaessa synkronoituu elokuvan ääniraidan kanssa. Näin kuvailutulkkaus on kenen tahansa elokuvissakävijän käytettävissä, eikä erillisiä kuvailutulkattuja näytöksiä tarvita. Nykyisin Suomen elokuvasäätiö kannustaa elokuvatuotantoja kuvailutulkkaukseen tuotantotuella. Tähän mennessä

3 Esseen toinen kirjoittaja, Maija Hirvonen, on lukuisia kertoja havainnollistanut näkevälle yleisölle audiovisuaalisen kulttuurin kokemista sokean kannalta niin, että yleisö on kuunnellut elokuvaa silmät kiinni. Kokemus tuntuu olevan monelle näkevälle yllättävä juuri siksi, että äänimaailma koetaan niin rikkaana ja moniulotteisena. 
valtakunnalliseen levitykseen ovat tulleet vain muutamat kuvailutulkatut kotimaiset draama-, komedia- ja lastenelokuvat: ${ }^{4}$

- Ylen Kotikatsomossa: Varpuset (2005), Puolin ja toisin (2013), Orkesteri (2015) sekä minisarjat Virginie (2009) ja Tauno Tukevan sota (2010);

- elokuvateattereissa Miekkailija (2015), Onnelin ja Annelin talvi (2015), Hymyilevä mies (2016), Salainen metsäni (2017);

- DVD-elokuvina Postia pappi Jaakobille (2009), Risto Räppääjä ja polkupyörävaras (2009), lisäksi Miekkailija, Onnelin ja Annelin talvi ja Hymyilevä mies.

Sokeaa kuvailutulkatun ohjelmiston vähäisyys harmittaa. Näytelmissä ja elokuvissa, joita ei kuvailutulkata, kokee aina väistämättä pitkästymisen hetkiä. Lieväkin turhautumisen kokemus herpaannuttaa mielenkiintoa ja saa ajatuksen harhailemaan. Toisaalta vaikeatajuiselta ja sekavaltakin kuulostava esitys saattaa olla kuvailutulkattuna selkeä, ymmärrettävä ja mielenkiintoinenkin.

Ylen menestyssarja Sorjonen on kouluesimerkki kuvailutulkkauksen tarpeellisuudesta. Raakojen rikosten ja häikäilemättömän juonittelun tapahtumapaikkana on kesäinen Lappeenranta kauniine järvimaisemineen, arvokkaine kulttuurikohteineen ja vilkkaine karjalaisine asukkaineen. Laatusarjan saama kansainvälinen suosio perustuu tähän väkivaltaisten tapahtumien ja idyllisen kaupunkiympäristön vastakohtaisuuteen. Ilman kuvailutulkkausta Sorjonen jää sokealle katsojalle yhdeksi rikossarjaksi lukemattomien muiden joukossa.

Miekkailijan kuvailutulkkaus on Ojasen mielestä suoranainen helmi. Vaikka elokuvan kuvailutulkkauksen perusteella ei opi miekkailemaan - oppisiko sitten katsomalla, mene ja tiedä - keskeinen dramaattisuus ottelutilanteissa tulee selkeästi ilmi. Eläytyvän miesäänen lukema äänitekstitys ${ }^{5}$ ja neutraalin naisäänen kuvailutulkkaus tekevät tarinasta helposti seurattavan ja nautittavan kokemuksen, esimerkiksi näin:

Liikuntasalissa Endel seisoo painonnostotelineen luona, koskettaa kengänkärjellä maassa makaavia painoja, katselee penkin repaleista verhoilua. Endelillä on kädet taskussa ja kasvoilla turhautunut ilme. Seinällä on käpristynyt Stalinin juliste.

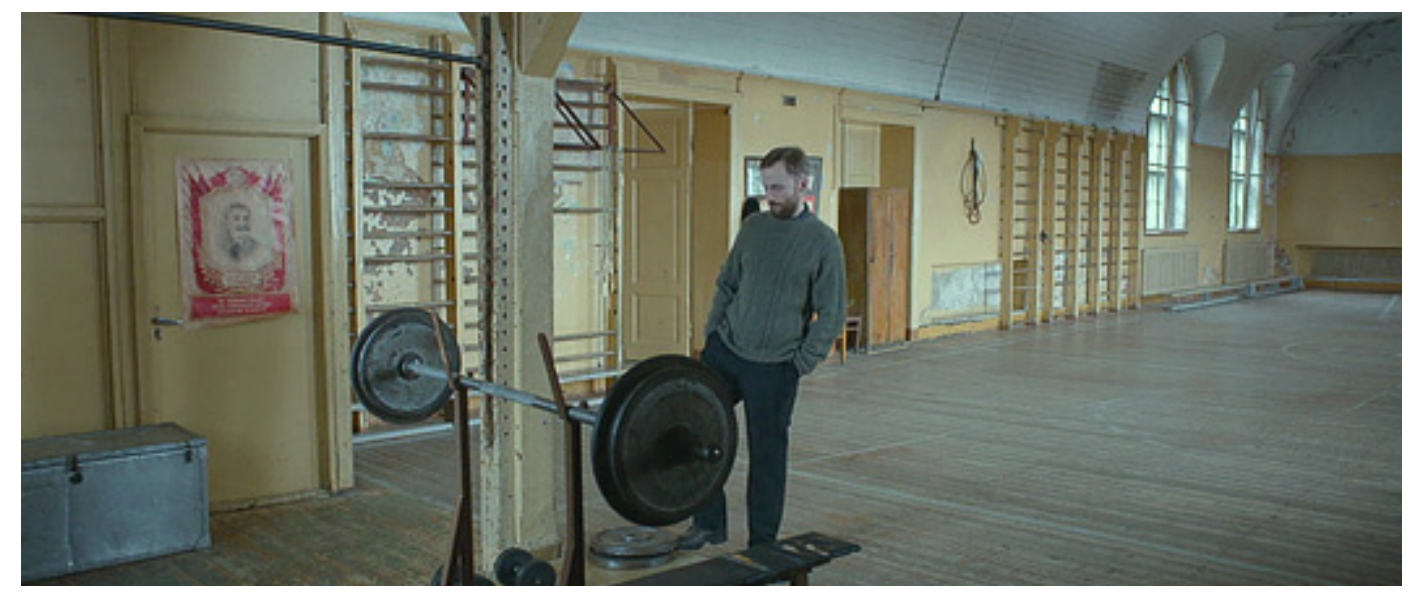

Kuva 1. Otos Miekkailija-elokuvan kohdasta 00:07:32. (C) 2015 Making Movies, Kick Film $\mathrm{GmbH}$, Allfilm.

4 Tässä lueteltujen elokuvien lisäksi pyydämme huomaamaan, että kuvailutulkkausta hyödynnetään myös muilla kulttuurin aloilla, kuten teatterissa ja museoissa, joista uusimpina esimerkkeinä uudistuneen Muumimuseon kuvailutulkkaus mobiilisovelluksessa sekä Serlachius-museoiden keskeisten teosten kuvailutulkkaus internetissä (ks. Kuvailutulkkaukset).

5 Kuvailutulkatuissa elokuvissa äänitekstitys toteutetaan eri tavalla kuin televisiossa: se on ihmisen, usein ääniammattilaisen, tuottamaa lukupuhetta. Ojasen mielestä inmisen lukeman tekstityksen kautta puheen sävyä on helpompi tulkita, samoin puheen rytmitys onnistuu ihmiseltä paremmin kuin koneelta. 
Vintillä valo pilkottaa kattotiilien välistä. Puisesta kattorakenteesta roikkuu valkoisia balettimekkoja. Aurinko siivilöityy valkoisen tyllin lävitse. Endel katselee ympärilleen, tarttuu yksinäiseen nahkaiseen luistimeen, päästää sen kädestään.

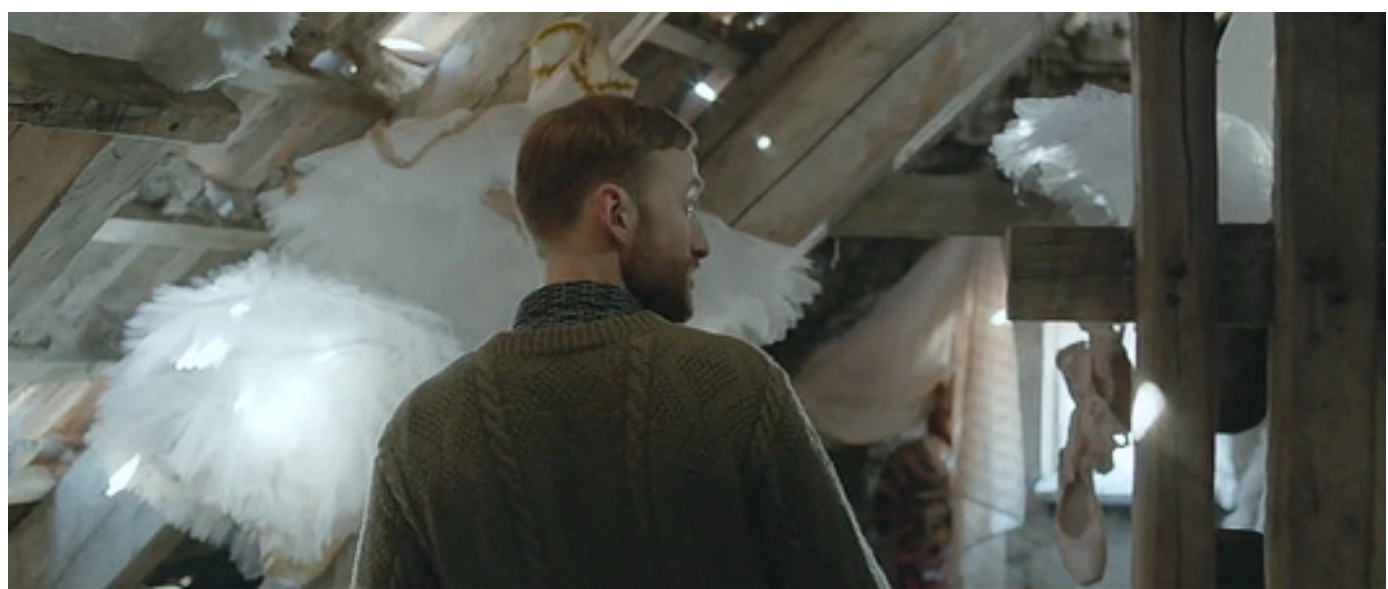

Katkelma on Miekkailija-elokuvan kuvailutulkkauksesta ${ }^{6}$. Tässä kohtauksessa päähenkilö Endel vaeltelee tutustumassa koulurakennukseen, jossa hän on juuri aloittanut työt liikunnanopettajana. Kohtauksessa ei ole dialogia, joten kuvailutulkkaus on pitkä, yhtenäinen kuvaus tapahtumien sarjasta. Kirjoitettu katkelma antaa kuvailutulkkauksesta kirjallisen vaikutelman, koska elokuvan äänimaailmaa ei ole merkitty ja puheen prosodiset eli ääni-ilmaisuun liittyvät elementit ovat poissa. Esimerkiksi se, miten kuvailutulkki painottaa ja tauottaa puhettaan, ei katkelmasta näy. ${ }^{7}$ Se kuitenkin havainnollistaa, miten kuvailutulkkaus ilmentää elokuvan visuaalista sisältöä kuvailemalla paikkoja, hahmoja ja toimintaa sekä valaistusta ja lavastusta.

Kuvailutulkkauspalvelun lisäämisen ohella kehitteillä on myös automaattisia keinoja tuottaa kuvailuja. Sosiaalisessa mediassa pilotoidaan koneen tuottamia tekstivastineita valokuville (ks. Facebook-ohje). Myös videoiden automaattinen kuvailu on intensiivisen kehittelyn kohteena, ja parhaillaan siinä ollaan siirtymässä sana- ja käsitetason kuvauksista lausekuvauksiin. Näin yksittäiset kuvasta tunnistetut asiat hahmottuvat kokonaisuuksiksi: esimerkiksi asioista body parts 'ruumiinosia', outdoor 'ulkona', building 'rakennus' ja suits 'pukuja' tulee tapahtuma a man in a suit and tie standing in front of a building 'mies, jonka päällä on puku ja kravatti, seisomassa rakennuksen edessä' (Lautenbacher \& al. 2015). Toisin kuin automaattinen kuvailu, ihmisen tuottama kuvailu(tulkkaus) on lähtökohtaisesti lausemuotoista, kokonaisuuksia hahmottavaa, ja ulottuu sisällöltään yksittäisten kuvaruutujen yli otoksiin ja useassa otoksessa tapahtuvaan toimintaan. Vaikka koneen tuottama kuvailu on vielä lapsenkengissä verrattuna ihmisen tuottamaan tarkkaan kuvailutulkkaukseen, sillä on merkitystä audiovisuaalisen ja visuaalisen kulttuurin saavutettavuudessa. Automaattiset tekstivastineet voisivat toimia, kuten konekäännökset kieltenvälisessä kääntämisessä, tiedonhaun välineinä ja keskeisen informaation välittävinä "pikakuvauksina". Ne olisivat tyhjää parempia vihjeitä siitä, mikä kuvassa kulloinkin on meneillään. Esimerkiksi draamasarjojen henkilöhahmojen ilmerepertuaari saisi kaipaamaansa lisävalaistusta, jos voitaisiin hyödyntää kasvonilmeiden automaattista

6 Kuvailutulkkauksen ovat tehneet Anu Aaltonen, Heikki Ekola ja Carita Lehtniemi

7 Tilan säästämiseksi emme tässä rupea kuvaamaan kuvailutulkkauksen tarkempaa litterointia vaan ohjaamme lukijan tutustumaan esim. Hirvosen (2016) artikkeliin.
Kuva 2. Otos Miekkailija-elokuvan kohdasta 00:07:54. (C) 2015 Making Movies, Kick Film $\mathrm{GmbH}$, Allfilm. 
tunnistamista - olkoonkin, että ilmeiden ja muun ei-kielellisen viestinnän kuvailuun liittyy monenlaisia tulkintaongelmia, kuten kulttuuri- ja kontekstisidonnaisuus (ks. esim. FaceReader).

\section{Epilogi: valonpilkahduksia}

Miten sokeat oppivat visuaalista tai audiovisuaalista lukutaitoa? Myöhemmin sokeutuneet harjaantuvat siinä ensin itse näkemällä ja sitten palauttamalla mieleen visuaalisia muistoja. Pitkään sokeina olleet ja syntymäsokeat puolestaan "nappaavat" tietoa sieltä täältä, kuulon kautta, samoin kuin näkevät visuaalisesti. Esimerkiksi värit opitaan yhdistämään tiettyyn asiayhteyteen ja niistä syntyy assosiaatioita, aivan kuten näkevillä. Aktiivinen näkövammaisuus on myös sitä, että osallistuu audiovisuaalisen kulttuurin tekemiseen. Ronja Oja, nuori sokea nainen, kertoo blogissaan (http://ronjaoja.blogspot.fi) tehneensä videon YouTubeen osallistuakseen kilpailuun. Videoblogien ja tubettajien aikakaudella tämä, jos mikä, on osoitus osallisuudesta!

Saavutettavuus on monenlaisten kokemistapojen mahdollistamista ja siksi sitä ei tarvitse käsittää pelkästään marginaalien tai erityisryhmien palvelemisena. Saavutettavuus ja siihen liittyvä intermodaalinen eli ilmaisukeinosta toiseen tapahtuva kääntäminen mahdollistavat kenelle tahansa toisenlaisia tapoja kokea ja osallistua audiovisuaaliseen kulttuuriin. Sitä paitsi marginaalisesta ilmiöstä voi kehittyä massiivinen hyöty, kun intermodaalisen kääntämisen kautta saadaan uusia keinoja kokea ja käsitellä multimodaalista viestintää ja aineistoa. Esimerkiksi kuvailutulkkausta voidaan hyödyntää metadatan ja sisällönkuvailumenetelmän kehittämisessä, jolloin se auttaa audiovisuaalisten sisältöjen löytämistä vaikkapa televisio- ja elokuvaarkistoista (Salway 2007). Kuvailutulkkauksen ja sisällönkuvailun kautta kerrytetään tekstikorpuksia audiovisuaalisen ja visuaalisen kulttuurin tuotteista, ja tällaiset korpukset palvelevat käyttäjiä mediakirjastoissa ja toimivat aineistona historian- ja kulttuurintutkijoille. Laajat korpukset ja uudenlaiset aineistonkäsittelyohjelmat mahdollistavat uudenlaisia, kvantifioivia lähestymistapoja audiovisuaaliseen kulttuuriin ja historiaan (vrt. Seppälä 2017). Kielellisen sisällönkuvailun avulla voisi tehdä hakuja ja koostaa yhteenvetoja sisällöltään tai jopa tyyliltään tietynlaisista otoksista: esimerkiksi paikkaa tarkoittavien prepositiolausekkeiden voisi olettaa viittaavan laaja- tai yleiskuviin tai muihin sellaisiin kuvakokoihin, jossa tapahtumapaikka on näkyvissä (vrt. Hirvonen 2012). Tekstimuotoiset korpukset mahdollistavat myös automaattisen sisällönanalyysin, kuten vaikkapa elokuvien kuvaston ryhmittelyn lausesemantiikan ja eksistentiaalilauseiden mukaan (pöydällä on juomalasi; vrt. paikkaa kuvaava lause juomalasi on pöydällä). Kuvailutulkkaus auttaa siten meitä kaikkia - näkeviä tai sokeita - näkemään enemmän.

\section{Lähteet}

Facebook-ohje. <https://www.facebook.com/help/216219865403298?helpref=faq_content> (Linkki tarkistettu 6.10.2017).

FaceReader. <http://www.noldus.com/facereader/facereader-6-automatic-facial-expression-analysisand-emotion-detection> (Linkki tarkistettu 6.10.2017).

Finnpanel (2015) Television katselu Suomessa 2014.<https://www.finnpanel.fi/lataukset/tv_vuosi_2015. pdf> (Linkki tarkistettu 6.10.2017).

Hirvonen, Maija (2012) “Contrasting Visual and Verbal Cueing of Space - Strategies and Devices in the Audio Description of Film". New Voices in Translation Studies 8, 21-43. 
Hirvonen, Maija (2013) “Perspektivierungsstrategien und -mittel kontrastiv: Die Verbalisierung der Figurenperspektive in der deutschen und finnischen Audiodeskription". trans-kom: Zeitschrift für Translationswissenschaft und Fachkommunikation vol. 6:1, 8-38.

Hirvonen, Maija (2016) "Multimodaalisen aineiston analyysi ja havainnollistaminen kuvailutulkkauksen tutkimuksessa". Teoksessa Eliisa Pitkäsalo \& Nina Isolahti (toim.) Kääntäminen, tulkkaus ja multimodaalisuus. Menetelmiä monimuotoisten viestien tutkimiseen. Tampere: Tampereen yliopisto, 122-138.

Hirvonen, Maija \& Schmitt, Reinhold (valmisteilla) “Blind-sighted interaction and the organization of work in the making-of audio description".

Hirvonen, Maija \& Tiittula, Liisa (2012) "Verfahren der Hörbarmachung von Raum. Analyse einer Hörfilmsequenz". Teoksessa Hausendorf, Heiko; Mondada, Lorenza \& Schmitt, Reinhold (toim.) Raum als interaktive Ressource. Tübingen: Günter Narr, 381-427.

Kortti, Jukka (2016) Mediahistoria. Viestinnän merkityksiä ja muodonmuutoksia puheesta bitteihin. Helsinki: Suomalaisen Kirjallisuuden Seura.

Kuvailutulkkaukset / Näyttelyt / Serlachius Museot. <http://www.serlachius.fi/fi/nayttelyt/kuvailutulkkaukset/> (Linkki tarkistettu 6.10.2017.)

Lacey, Simon \& Lawson, Rebecca (2013) “Introduction”. Teoksessa Simon Lacey \& Rebecca Lawson (toim.) Multisensory Imagery. New York: Springer, 1-8.

Lautenbacher, Olli Philippe; Tiittula, Liisa; Hirvonen, Maija; Laaksonen, Jorma \& Kurimo, Mikko (2015) "Towards Reliable Automatic Multimodal Content Analysis". Proceedings of The Workshop on Vision and Language 2015 (VL'15) - VISION AND LANGUAGE MEET COGNITIVE SYSTEMS, 6-7. <http://www. emnlp2015.org/proceedings/VL/pdf/VL03.pdf> (Linkki tarkistettu 6.10.2017).

Ojamo, Matti (2015) Näkövammarekisterin vuosikirja. THL \& Näkövammaisten liitto ry. <http://www. nkl.fi/fi/etusivu/nakeminen/julkaisu/nvrek_vuosikirja> (Linkki tarkistettu 6.10.2017).

Salway, Andrew (2007) "A corpus-based analysis of audio description". Teoksessa Jorge Díaz Cintas, Pilar Orero \& Aline Remael (toim.) Media for all: subtitling for the deaf, audio description and sign language. Amsterdam: Rodopi, 151-174.

Seppälä, Jaakko (2017) "Cinemetrics ja metrinen tyylintutkimus". Lähikuva vol. 1, 46-53.

Silfverberg, Anu (2017) "Miksi toteuttaa kauneusihanteita, joita inhoaa?". Image, 12.4.2017. <http:// www.image.fi/image-lehti/miksi-toteuttaa-kauneusihanteita-joita-inhoaa-anu-silfverbergin-hienoessee> (Linkki tarkistettu 6.10.2017).

Sobchack, Vivian (2004) Carnal Thoughts: Embodiment and Moving Image Culture. ProQuest Ebook Central: University of California Press.

Spence, Charles \& Deroy, Ophelia (2013) "Crossmodal mental imagery”. Teoksessa Simon Lacey \& Rebecca Lawson (toim.) Multisensory Imagery. New York: Springer, 157-183.

Tiittula, Liisa (2007) "Blickorganisation in der side-by-side Positionierung am Beispiel eines Geschäftsgespräches". Teoksessa Reinhold Schmitt (toim.) Koordination. Studien zur multimodalen Interaktion. Tübingen: Gunter Narr, 225-262.

WHO $=$ World Health Organization (2014) Visual impairment and blindness. Media Centre. Fact Sheet $N^{\circ}$ 282. <http://www.who.int/mediacentre/factsheets/fs282/en/> (Linkki tarkistettu 6.10.2017). 